This intervention argues that our understanding of negative emotions is underdeveloped due to the urge to expel negativity from the personal and political spheres. By invoking the antagonism of Chantal Mouffe's philosophy, the article provides a conceptual grounding of pity, hate, and resentment by explaining these emotions based on whether the person feeling them sees the other as inferior, equal, or superior. For the Left, the intervention argues, a better understanding of these emotions will help people think through their own antagonisms, to counter accusations that all Left opposition is mere resentment, and to promote solidarity. Finally, the article seeks to hold open a space for a hatred that is neither pathologised nor eradicated. 


\section{Pity, Hate, Resentment, and the Left}

\section{MURDOCH STEPHENS}

The triumverate of pity, hate, and resentment are poorly understood and yet regularly invoked as both personal and political logics. ${ }^{1}$ An accusation of pity, hate, or resentment functions as an ad hominem-'oh, he's just a hater'-or as a crude simplification - 'the Left is driven by a politics of resentment'. The aim of this intervention is to reflect on these kinds of accusations after the fact, once the heat of it has passed. I want to reflect on these accusations by delving into each of the three antagonisms, suggesting how they relate both to one another and to a general negativity. The intervention becomes redemptive, not of the Left, but of the validity of the emotional experience of the three concepts. In particular, I want to offer a schema for people to recognise pity and resentment so that they can level those feelings into an egalitarian, though still negative, hate. ${ }^{2}$

Pity, hate, resentment: everyday words with meanings rarely debated. The lack of understanding of these words extends from the personal sphere ('I pity you'; 'you hate me') through to the political sphere ('we hate them'; 'they resent

1 I would like to acknowledge Jack Foster and Dylan Taylor who I owe affection to (see Table 1) for their careful reading of an earlier version of this intervention as well as their stewardship of Counterfutures.

2 It would be remiss to end this first paragraph without at least alluding to Nietzsche, who I (briefly) turn to in the coming pages. 
us'). Each refers to a negative emotional state directed at another person or group. But where the words differ is in how the individual values, or does not value, the person subjected to their antipathy. Resentment is when we dislike someone who we see as superior to ourselves. Pity is when we dislike someone who we see as inferior to ourselves. But when we see ourselves as equal to the person we dislike then that negative sentiment takes the form of hate.

\begin{tabular}{|l|l|l|l|l|}
\hline \multicolumn{2}{|c|}{} & \multicolumn{2}{|l|}{ Type of feeling } \\
\cline { 3 - 5 } \multicolumn{2}{|c|}{} & Positive & Moderate & Negative \\
\hline $\begin{array}{l}\text { Relation of } \\
\text { other to the } \\
\text { self }\end{array}$ & Better than I & Admiration & Respect & Resentment \\
\cline { 2 - 5 } & Equal to I & Affection & Esteem & Hate \\
\cline { 2 - 5 } & Worse than I & Acceptance & Tolerance & Pity \\
\hline
\end{tabular}

Table 1. Emotional relations to valuing another. ${ }^{3}$

Looking into the personal feelings of pity, hate, and resentment are undoubtedly of use as we try to understand some of our negative reactions to others - whether they be comrades or cousins. But for this Counterfutures intervention, as with my article 'Pākehā as Punisher' in issue four, my aim is to take a relation that we understand from the intimate sphere and

3 I hesitated to form the three-part distinction between pity, hate, and resentment into a matrix that also gave names to emotions that represented moderate and positive attitudes. That hesitation came through in my naming of the emotions that would fall in each box. I'm no structuralist. I don't think that the words I've put into boxes should have lines between them. The matrix is intended only as an exploratory foray into a terrain that I hope others will also wish to survey so that the subject matter might receive further analysis, description, and use. In approximating this topology, we are able to contrast a positive schema against the negative. We can also discern a middle-ground, where the passions dip into the kind of neutrality that some might think make for civil politics. 
transpose it to the political sphere. ${ }^{4}$ In this case, this movement involves using examples of the three negative feelings in the personal sphere to help political agents understand their relationship to political adversaries.

\section{Political antagonisms and emotions}

The work of Chantal Mouffe offers one way to understand the recent history of political antagonism. ${ }^{5}$ Mouffe's principle task is to foreground antagonism and dissent against Habermas and Rawls's focus on striving for agreement and consensus. Mouffe's work takes form through 'agonism'-a type of antagonism that recognises the rights of all parties to exist and to participate in debate as legitimate actors. An example of agonism can be found in the competition of sport: we might hate the opposition with a curious fury, but we accept — and even promote — their right to play the game. In contrast, a blunt antagonism would occur if a sporting event spilled off the field of play into a violence unsanctioned by rules.

Mouffe critiques Habermas's consensus politics for delimiting participation in political decisions to rational actors. Rationalism was required for these consensus systems because it supposedly paved the way for a politics that could go beyond the single-minded self-interest described by Schmidt. In contrast, any actor who was irrational could be excluded from decision-making because they would not be able to follow the process of recognising the other and working towards a common understanding in the public sphere. Mouffe is right to be suspicious of the way that the demand for rationalism would manifest as a tool of exclusion. For example, one aim in defining some political groups as terrorist organisations is to undermine their legitimacy to participate in political negotiations. Consider the fraught balance of the Taliban, for example, on the edge of negotiations

4 Murdoch Stephens, 'Pākehā as Punisher-Dominated Conversations on Dominant Cultures,' Counterfutures no. 4 (2017): 185-191.

5 See Chantal Mouffe, The Democratic Paradox (London: Verso, 2000) and Agonistics: Thinking the World Politically (London: Verso, 2013). 
with the Afghan government and the United States-led forces. ${ }^{6}$

But Mouffe is not just the antithesis of Habermas and Rawls: her work marks a circling back to, and a synthesis beyond, the all-againstall antagonisms of earlier thinkers like Schmitt. Antagonism becomes agonism when the various interests that split groups are no longer seen as insurmountable or desirable. In short, Mouffe's agonism is pluralist where Schmitt's antagonism is not.

Across these discussions of how to embark on political communication and who is included, little attention is paid to the emotional tone of political expression. While the excluded irrational behaviour must give some indication that it cannot be trusted, there is no discussion of the emotions of agreement and agonism. Why might animating emotions be elided when theorists consider antagonisms in the political sphere? Perhaps studying the emotions of antagonism unnecessarily complicates things when there are other arguments that one is seeking to make. For us to understand enduring disagreement, I think we need to turn to some examples where emotional responses—-such as pity—congeal or fester.

\section{Pity}

My strongest memory of pity is from my first year at the University of Otago. It was lunchtime and I was walking from the university to my dorm. My memories are a little hazy, but I sense that it was a still, overcast day. It was not so cloudy that the hills hemmed in the cloud, but just enough to feel like the murky grey of the sky was a mirror of the ocean. These days are a common occurence in Otago, but rarer in the plains of Canterbury and almost impossible in Auckland and Wellington. I walked along Queen Street. It was a minor road, terraced into the hill and almost the complete opposite in all imaginable manner from the long

6 I would argue that Mouffe is only able to be more open to actors who are considered outside the bound of rationalisms. The impetus of all of the models of consent and antagonism are on moving towards dialogue and agreement and at some point all of these scholars come up against the hypothetical example of a negotiant who is at the limit of our ability to make sense of them. 
one that runs through Central Auckland.

From a distance I saw a woman, doubled over in the driver's seat of her car. Whenever she righted herself, her eyes darted about the street before ducking her head down as if attempting to hide from some unknown spy. As I drew up alongside the car I matched her furtive gestures with a crime: she was demolishing a bucket of KFC. Having come from a small farming town, KFC was always something I associated with the city. But even so, I'd never seen a real bucket before - all those battered limbs of chicken piled up and coated with those herbs and spices. I knew nothing of the woman but sensed a shameful transgression. I walked on without pausing. And I pitied her.

If we want to have a richer conception of the legitimacy of antagonism it is useful to turn to the murkier question of how we value others. If we consider pity and resentment we find a relation between the self and other that is not that of equals. If we are not equals, then the relationship of the worthy adversary that is so central to Mouffe's agonism becomes difficult, perhaps impossible.

Consider the personal case made above: I pitied the woman eating KFC alone in her car. Why? I've thought about this many times. I wasn't a vegetarian at the time, so it wasn't that. Could it be the racial or class signifiers of fried chicken? Perhaps that had something to do with it. Would I be as equally pitying if the woman had been tucking into a panini? But on reflection, the crux of the experience was the furtive glance. That glance revealed a face distorted with shame, pleasure, and fear. I feel that my pity was justified, even though I sympathise with her situation. But I could have read it all wrong. Maybe she was listening to the radio and her expression was not the result of everything that I have projected onto her but rather a winsomely left response to her lunchtime pleasure being sullied by Leighton Smith. ${ }^{7}$

7 Leighton Smith is an Australian-born talk-back radio host who was grating liberals and leftists alike from a time before Sean Plunket's or Mike Hosking's voices had broken. The author maintains a particular animosity to Smith due to one of the presenter's sneering diatribes about the author's ultimately successful 'Doing Our Bit' campaign to double New Zealand's refugee quota. 
A politics motivated by pity is undesirable for the Left for two reasons. First, if pity is extended from the personal to the political then it is also expanded across a massive scale. While the pity shown in the example above can be thought through-e.g. maybe she wasn't really ashamed of the fried chicken-extending this example to pity an entire category of people means that it becomes a categorical truth. In this case, that truth places the Left in a position of superiority to the average person that we seek to work alongside. As one reviewer of this intervention noted, in pitying we see the target of our actions as worse than us, which is problematic as it creates an idealised other (the poor and downcast, who we pity and wish to raise above their low station). This idealised other dehumanises those we imagine ourselves aligning with. By contrast, the reviewer noted, the philanthropy of the Right is well-suited to this position, as it allows them to bolster their own sense of superiority and the 'natural order' of which they are at the pinnacle.

The second shortcoming of pity as a political strategy applies to the adversary rather than a broad public. Pity works to deflate any threat our adversaries might pose. For example, the alt-right incel figure is dismissed as a serious political force because of their pitiable attempt to find a positive identity on the basis of their rejection by women. These dismissals are most troublesome when they stand-in for taking action against such a figure.

Viewing the other as inferior undermines the broad democratic base of the Left. A challenge for middle-class leftists in forging an alliance with the working class are socio-cultural differences that are, frankly, barely important. But it is these socio-cultural factors - things like white bread or preferred brand of beer-that make up a lot of attempts by people to show their worth. While conspicuous displays of worth can involve creativity or imagination, more often than not they are simply raw displays of wealth. Pitying someone who either can not, or refuses to, participate in these fashions is a distraction from the abilities of people to forge political alliances. Those political alliances often require traversing real differences in race, gender, and class for which consumption choices can stand in as a proxy. Pitying these choices-even when there are justifiable reasons to do 
so in terms of quality-is just one more way that solidarity crumbles into inane division.

Before turning to a relational and emotional stance to the adversary that could be more useful, I need to consider an inverse to pity: resentment. Not all situations of pity would also involve resentment, but where pity sees the other as worse than us, resentment flips this position: the other is seen as better than us.

\section{Resentment}

I resent my ex. An ex. She has moved on: marriage, mortgage, children, career. I have not, or I have not moved on so much as I have siddled off on my own, sullen way. I recognise my negative feelings towards her and recognise that they come from the difficult place of thinking that she is better than me.

What about resentment? Admissions of resentment are rare and curious. It is hard to boast that one is resentful because it is also a statement of inferiority. Most of the everyday admissions I have heard come with an implication that the inferiority is partial, and may soon be resolved: I resent my friend's good fortune; I resent waiting in a queue.

In my example, the reader should wonder about the truthfulness of my resentment. Do I truly see my ex as better than me if I can see the situation so clearly? Perhaps there is a catch-22 at play: anyone able to admit their resentment isn't really inferior as their admission requires the strength to abandon the tools we use to protect ourselves from feeling inferior. But we can also imagine my admission as a ruse: I say that I recognise my resentment so as to project my reasonableness and clear-thinking. I say that I am resentful to create the conditions for no longer being resentful. Speech has such a power!

Many books have been written on how to extricate oneself from the psychological overinvestment in another, or cathexis. While I won't go into the work required to redeem one's self and, in turn, our view of those who 
we resent, I do want to gesture to Kierkegaard's Either/Or. ${ }^{8}$ In that work, cocooned away from his own cursed romance by a series of pseudonyms and literary methods, he turns the tables on resentment to describe the best way for a resented lover to cool the jilted. The long and short of Keirkegaard's advice is to balance the relationship away from resentment through a display of affection for a new, pitiable partner. This display, he argues, will lead to a re-evaluation of the object of affection. The lesson, as in the approximations in the matrix in Figure 1, is that we can change our value of another by changing how we value them or how they value us (better, equal, or worse than us), or how we see the relationship to them (positive, neutral, or negative).

The popularity of resentment as an accusation against the Left comes from right-wing uses of Nietzschean theories on Christianity and slave morality. ${ }^{9}$ From Nietzsche's view, the Christian faith grows from a resentment against the powerful. As the number of Christians grew they were able to extend their morality into a system of laws that subjugated the powerful and conquered their consciousness with an ethic that denies power and mutes human will.

The Nietzschean critique is transposed by the contemporary Right from the metaphysical space of a critique of good and evil (and valorisation of the will to power) to the economic space of a critique of inequality and exploitation. While the case could be made that today's economic critiques are merely an inherited subsystem of previous subsystems, the point feels opportunist. If economic critiques are always a function of resentment despite the material basis of the critiques, one wonders at what point the incisiveness of Nietzsche's metaphysical critique is overdone.

The concept of resentment is used by the Right in a curious bit of circular accounting that explains away almost all antagonistic political relations. The reasoning of the Right goes like this: the poor are lefties

8 Søren Kierkegaard, Either/Or: A Fragment of Life (London: Penguin Classics, 1992).

9 Friedrich Nietzsche, On the Genealogy of Morality: A Polemic (Oxford: Oxford University Press, 2008). My reading of resentment was informed by the work of Kathleen Higgins and Robert Soloman, most notably: What Nietzsche Really Said (New York: Schocken, 2001). 
because they envy the wealthy. If they were no longer poor, they would no longer be left-wing. The Left, to the Right, is institutionalised resentment. The Right assumes that the poor (and Left, by proxy) see their economic conditions as the entire basis of their being. In this worldview, all critiques of capitalism (and the resulting inequities) are grounded not in any actual economics or politics but in the psychological shortcomings inherent to poverty. ${ }^{10}$ Poverty, to the Right, determines the worldview of the poor and the Left and neccesarily leads them to the logical recognition of their own inferiority. It should be easy to reject this view by claiming that there are more important things in the world than money, but this reductive logic seems as doggedly enduring as capitalism itself.

The value of a critique of both pity and resentment for the Left should now be obvious: it offers a riposte to the Right's attempt to ground leftist politics in infantile jealousies and buffers the Left against the inward turn to moral superiority. But if we reject the idea that the Left is animated by resentment, and if pity is not a viable strategy for distancing ourselves from those we oppose, does that mean we need to simply drop the negativity and find some common ground? Maybe the Left could lighten up on the capital-C Critique of capital-C Capitalism a bit, but I would argue that there must still be a place for antagonism. The antagonism that I would make space for is called hate, an emotionality that treats adversaries as equals even if we don't see eye-to-eye. ${ }^{11}$

\section{Hate}

I hate my landlord. Our rent has just been increased by 10 percent and yet they leave the downstairs flat empty while they decide whether to renovate it or not. If money were the problem then you'd think they would have timed

10 One can imagine that the same would have applied to feudalism: 'The serfs are merely jealous that they are not ordained with royal blood as decreed by God'.

11 I'm thinking, here, of invoking J.K. Gibson-Graham, The End of Capitalism (as We Knew It): A Feminist Critique of Political Economy (Oxford: Blackwell, 1996) or perhaps just a bit more critique that is grounded in a reading of capital-C Colonisation. 
the renovations with kicking the previous tenants out. We ask them, via the property management company, to fix the front door and if we can have a cat. The first question is ignored, the second is rejected. I've never met them, but I hate both them and the property manager.

The Soviet poet Vladimir Mayakovsky released a set of poems with the rare distinction of being legible in both the Cyrillic of Russian and the Latin script of English: HATE! ${ }^{2}$ Those four letters, if read in English, speak of the intense emotion of an aggressive antipathy. Hate is so foundational that it barely needs explanation. In Mayakovsky's Russian, HATE! means 'here you are!' His assertion explodes: 'I've found you! I've found the real you! The lost but essential, you! You are hate. And you were obscured . . . but now you are found!' For Mayakovsky, an emblematic but troubled figure for Bolshevik poetry, this rich word play was his contribution to a social struggle that eventually had no use for his passions. Here you are!

The most useful emotional relation to a political adversary is hatred. In the manner recognised by Mouffe, we recognise them as equals with a right to exist in the political space, but nevertheless we deeply oppose them, their practices, and/or their beliefs. Hatred is valid and can be effective if its intensities are channeled into political action. By describing the need to channel the intensities of hatred into political action I am not suggesting that hatred becomes tampered down into a more reasonable, friction-less discourse. Nor am I suggesting that there is something singular about hatred that other emotional states do not possess-love could be equally balanced and useful and has been the subject of many personal and political enquiries. Hate, in contrast to love, is at something of a loose end. There is an instructive anecodote at the beginning of Semiotext(e)'s Hatred of Capitalism where Sylvere Lotringer (S) is chatting to Chris Kraus (C):

S: What happened is that we forgot that capitalism even exists. It has become invisible because there's nothing else to see. When I told Baudrillard about

12 Vladamir Mayakovsky, HATE! (Kharkov: Folio, 2009). 
this book, he said the title sounded too old-fashioned.

C: He didn't get the joke. ${ }^{13}$

Lotringer and Kraus's view of hatred is two-fold: first as a throw-back, then as a laugh. Hatred, at that odd point in time-a decade after the end of the Cold War but before the new American quagmires-was something either best left to the cavemen or that could be joked about knowingly. The first verso of the collection explains where the title actually came from: a response from film-maker Jack Smith to the journal name Semiotext(e).

Listen: Hatred of Capitalism would be a much better title. It's stunning. The world is starving for thoughts. If you can think of something, the language will fall into place, but the thought is what's going to do it. ${ }^{14}$

For this intervention, Smith and Mayakovsky are patron saints. They express hate as an emotion of vigorous, creative opposition. ${ }^{15}$ A similarly vibrant approach to the animating powers of hatred come through in Sloterdijk's Rage and Time. ${ }^{16}$ Rage and Time repositions hatred through the concept of thymos. Thymos is the Ancient Greek term for a rage that one directs, rather than for a rage that takes over the body. As Couture summarises, thymos is the controlled, directed, and domesticated form of rage. ${ }^{17}$ Thymos is a form of rage that is both powerful and strategic. Hate need not be an irrational force prohibited from political struggle, but as

13 Chris Kraus and Sylvere Lotringer, 'Introduction: The History of Semiotext(e),' in Hatred of Capitalism, eds. Sylvere Lotringer and Chris Kraus (Los Angeles: Semiotext(e), 2002), 15-16.

14 Jack Smith, Epigram in Hatred of Capitalism, 4.

15 I would argue that hatred is a gendered performance, with descriptions like these more likely to be levelled at men who display hate rather than women. This is not to say that women don't hate, but that the way their hatred is received has less room for being seen as vigorous or creative.

16 Peter Sloterdijk, Rage and Time: A Psycho-Political Investigation (New York: Columbia University Press, 2012).

17 Jean-Pierre Couture, Sloterdijk (London: Polity Press, 2015). 
thymos can be deployed through a rhetorical rage. Rhetoric, in Sloterdijk's overview of the field, 'is the doctrine of controlling affects in political ensembles, is applied thymotics. ${ }^{18}$

Hate could be an antagonism that is not changed by being recognisedunlike resentment - as while the relation to the situation is negative, the relation to the other is one of equals. Schopenahuer uses the porcupine as a naturalised figure of antagonism that permeates a pessimistic society. As he tells it, the porcupine in winter is like the human in society. In winter the cold pushes the porcupine into close proximity with others in search of warmth. But as they get closer their quills intrude on one another and so the little mammals endure the sharpness of their collective company and are only rewarded with the most minimal of body heat. ${ }^{19}$ The story has an appeal to the misanthrope, but achieved wider fame when it was recalled by Freud-hence, a healthy recrudescene for the concept in books like those of Luepnitz and Warwick. ${ }^{20}$

But before Freud, Nietzsche had made reference of the porcupine as a mark of his late turn away from Schopenhauer and nihilism. In reflecting on his place in German towns he wrote:

In such circumstances should I not be compelled to become a hedgehog? But to have prickles amounts to a squandering of strength; they even constitute a twofold luxury, when, if we only chose to do so, we could dispense with them and open our hands instead. ${ }^{21}$

As with Nietzche's late turn to joy, our matrix is not just a tool to elaborate

18 Sloterdijk, Rage and Time, 15. Ironically, across a series of public-facing commentary in newspapers, Sloterdijk seems almost pathologically unable to recognise the sorts of economic exploitation that animate Left thought and practice.

19 Arthur Schopenhauer, Essays and Aphorisms (New York: Penguin, 2004).

20 Deborah Luepnitz, Schopenhauer's Porcupines: Intimacy and its Dilemmas: Five Stories of Psychotherapy (New York: Basic Books, 2013); Hugh Warwick, The Hedgehog's Dilemma: A Tale of Obsession, Nostalgia, and the World's Most Charming Mammal (London: Bloomsbury, 2004).

21 Friedrich Nietzsche, Ecce Homo: How One Becomes What One Is (New York: Algora Publishing, 2004), 32. 
on negative thoughts. There are other important emotions not discussed in this intervention: affection, admiration, acceptance, and even those from the ambivalent, or moderate sphere. Consider, for example, Papastergiadis, who aligns the ontologies implicit in Sloterdijk and Mouffe around antagonism and agonism, then challenges the reader to think of an alternative to this opposition as a grounding politics. ${ }^{22}$ And while that evocation of a politics beyond conflict - think co-operation or mutual aid-is not the writ of this paper, it could be a kind of compulsory detoxification required of any intervention that fixates a little too much on the negative.

To find hope in hate as an equaliser between resentment and pity might not be the end goal of most psycho-political investigations. But is the opposite-opening our hands or turns to joy—as infallible as works on love and peace might propose? Just as I have argued that the negative stance of hate can obscure an egalitarianism, so too can the positive rhetoric of love be used to disguise all sorts of contempt and corruption. Love thy neighbour? Well ... maybe . . but what of the landlord? As wages stagnate and rents leap ahead of our ability to pay, our hatred of the landlordexpunged of resentment, and without a cloying self-pity—may be the best response.

22 Nikos Papastergiadis, 'Does Philosophy Contribute to an Invasion Complex? Sloterdijk the Antagonist and the Agonism of Mouffe,' Journal of Aesthetics \& Culture 9, no. 2 (2017): 13-24. 